\title{
RETRACTED ARTICLE: Experimental Evaluation of Volume Stability of Rapidly-Cooled Steel Slag [RCSS] as Fine Aggregate for Concrete
}

\author{
Jin-Man Kim*, Sung-Hyun Cho**, and Eun-Gu Kwak***
}

Received June 27, 2012/Revised August 5, 2013/Accepted October 5, 2013/Published Online March 31, 2014

The editors of the KSCE Journal of Civil Engineering hereby retract the online first article "Experimental Evaluation of Volume Stability of Rapidly-Cooled Steel Slag [RCSS] as Fine Aggregate for Concrete" by Jin-Man Kim, Sung-Hyun Cho, and Eun-Gu Kwak, published on March 31, 2014 (DOI: 10.1007/s12205-014-0328-2). It has come to the editors' attention that the article has been translated into English, without appropriate reference, from an article written in Korean by some of the same authors and is already published in the Magazine of the Korea Concrete Institute, Vol. 19, No. 6, pp. 39-45 in November 2007. After a thorough investigation, it has been established that this ethical misconduct concerns duplicate publication and therefore, the editors have decided to retract this article from the journal. The editors deeply apologize to readers that this misconduct was not detected during the submission and review process.

*Member, Professor, Dept. of Architecture Engineering, Kongju National University, Cheonan 330-717, Korea (E-mail: jmkim@kongju.ac.kr)

**Member, Deputy Chief, Research Center, Hanil Cement Company Ltd. Daejeon 306-802, Korea (E-mail: csh8902@hanil.com)

***Member, Managing Director, ECM Technology Cheonan 330-717, Korea (Corresponding Author, E-mail: keg7707@kongju.ac.kr) 